\title{
Relationally Charged: How and When Workplace Friendship Facilitates Employee Interpersonal Citizenship
}

\author{
Jincen Xiao, Jih-Yu Mao*, Jing Quan and Tao Qing \\ School of Business Administration, Southwestern University of Finance and Economics, Chengdu, China
}

Having friends in the workplace not only provides an employee joy and meaning, but also facilitates one's positive behavior. In this study, we argue that workplace friendship has positive influence on an employee's interpersonal citizenship behavior. Drawing upon conservation of resources theory, the present study explores how and when workplace friendship fosters interpersonal citizenship. Using a time-lagged, multisource data of 620 employees from 83 workgroups, we found that workplace friendship increases an employee's relational energy, which subsequently, leads to greater interpersonal citizenship. Moreover, we discovered relational-interdependent self-construal as an important moderating influence that affects the saliency of this relationship. Specifically, for employee with a relational-interdependent self-construal,

OPEN ACCESS

Edited by:

Llewellyn Ellardus Van Zyl, Eindhoven University of Technology, Netherlands

Reviewed by: María del Mar Molero, University of Almería, Spain Leander Van Der Meij, Eindhoven University of Technology, Netherlands

${ }^{*}$ Correspondence: Jih-Yu Mao

jim.jy.mao@swufe.edu.cn

Specialty section:

This article was submitted to Organizational Psychology, a section of the journa Frontiers in Psychology

Received: 26 September 2019 Accepted: 27 January 2020

Published: 19 February 2020

Citation:

Xiao J, Mao J-Y, Quan J and Qing T (2020) Relationally Charged: How and When Workplace Friendship Facilitates Employee Interpersonal Citizenship. Front. Psychol. 11:190. doi: 10.3389/fpsyg.2020.00190 workplace friendship has a stronger positive influence on one's relational energy and hence interpersonal citizenship. Contributions to theory and practice are also discussed.

Keywords: workplace friendship, relational energy, interpersonal citizenship, relational-interdependent selfconstrual, conservation of resources theory

\section{INTRODUCTION}

Does having friends at work matter? How and why can friends affect a focal employee's behavioral outcome? According to a study conducted by Gallup, people who have a best friend at work are not only to be happier and healthier, they are also seven times more likely to be engaged in their jobs as compared to those who say otherwise (Rath, 2006). In reality, friendships are private interpersonal networks that widely exist in an organizational setting (Ingram and Zou, 2008). Workplace friendship describes the quality of interpersonal relationship between individuals in the workplace where the relationship is characterized by mutual trust, commitment, reciprocal liking, and shared interests or values, which are driven by communal norms and socioemotional goals (Berman et al., 2002; Pillemer and Rothbard, 2018). Organizational research has found workplace friendship to have positive influences on both the employees and organization such as enhanced job significance (Mao et al., 2012), team-member exchange (Tse et al., 2008), well-being (Craig and Kuykendall, 2019), and innovation (Lu et al., 2017).

Indeed, having friends at work not only can enrich and bring joy to an employee's organizational life (Rawlins, 1992; Sias and Cahill, 1998), but also can enable one to achieve a more successful career (e.g., Winstead et al., 1995; Ingram and Zou, 2008; Mao et al., 2012; Liu et al., 2013; Methot et al., 2016; Lu et al., 2017). Existing studies have found that workplace friendship can facilitate an individual's psychological and behavioral responses by enhancing one's affective experiences, such as happiness, excitement, trustworthiness, joy, and sympathy (e.g., Liu et al., 2013; Methot et al., 2016; Lu et al., 2017). Since friendship often elicits many of these positive emotions simultaneously, solely focusing on one particular emotion may not provide sufficient knowledge to 
understand the full picture of the positive influences of workplace friendship (Wright, 1984; Sias and Cahill, 1998; Ingram and Zou, 2008). Rather, these positive emotions form a collective force and provide the energy necessary to propel an individual's action (Quinn and Dutton, 2005; Fritz et al., 2011; Cole et al., 2012; Baker, 2019). Hence, in this study, we investigate the consequences of workplace friendship from an energy perspective, as the arousal and accumulation of affective experiences are important sources of individual energy. To explore this promising line of research, we adopt conservation of resources (COR) theory to develop our theoretical rationale because energy is seen as a valuable resource that facilitates an employee's behavior at work (Hobfoll, 1989).

Resource is something that a person values and can help an individual to attain one's goals (Halbesleben et al., 2014). One such goal related to workplace friendship that an individual is likely to strive for is to develop and maintain interpersonal relationships (Sias and Cahill, 1998). This is because in a work context, friendships are likely developed from interpersonal interactions that characterize mutual support, help, and consideration in order to establish trust, liking, and common interests (Berman et al., 2002; Ingram and Zou, 2008; Pillemer and Rothbard, 2018). Hence, we suggest that positive interactions with friends are likely to stimulate an employee's interpersonal citizenship behavior, and the key underlying influence is one's elevated energy.

As a heightened level of affective state, energy is seen as a renewable resource that connects workplace events and related outcomes (Quinn and Dutton, 2005; Cole et al., 2012; Quinn et al., 2012). For example, subordinates become energized when they receive a sense of calling and membership from their spiritual leaders, which in turn, make them more capable of performing their jobs (Yang et al., 2019). In this study, we are particularly interested in relational energy, which is defined as "a heightened level of psychological resourcefulness generated from interpersonal interactions that enhances one's capacity to do work" (Owens et al., 2016, p. 37), as its focus on energy generated from interpersonal interactions is in accordance with the interpersonal nature of workplace friendship. In essence, relational energy captures energy derived from social interactions (Baker, 2019).

Furthermore, the extent to which employees are affected by interpersonal relationships are dependent on how they construe themselves in relation to others (Gore et al., 2006; Morry and Kito, 2009; Cristina-Corina, 2012). For individuals with a relational-interdependent self-construal (RISC), they tend to emphasize their connectedness with others and strengthen existing relationships (Cross et al., 2000; Cross and Morris, 2003). Therefore, they highly value and are attentive to and affected by friends in the workplace (Gore et al., 2006). Consequently, we expect that employees with a RISC are more likely to be energized by workplace friendships.

By testing these propositions in a time-lagged multisource study, our investigation of the impacts of workplace friendship through the lens of COR theory offers several contributions to the literature. First, instead of examining specific emotions in facilitating work-related outcomes of workplace friendship, our research differs from previous studies by focusing on the accumulation of positive emotions as a source of energy that motivates an employee's interpersonal behavior (e.g., Winstead et al., 1995; Methot et al., 2016; Lu et al., 2017). In doing so, we approach from a different perspective and enhance understanding on the consequences of workplace friendship. Second, we identify relational energy as the key linking pin between workplace friendship and interpersonal citizenship. This finding sheds light on how workplace friendship influences interpersonal citizenship by suggesting that individuals can derive relational energy from workplace friends, which subsequently, drives them to help others. We also empirically answer Owens et al.'s (2016) call for exploring coworkers as a viable source of relational energy, as existing research has primarily associated relational energy with leadership behavior (e.g., Wang et al., 2018; Yang et al., 2019). Third, we incorporate RISC to understand how individual relational energy and thus demonstration of interpersonal citizenship as consequences of workplace friendship are affected by one's interpersonal tendency. As such, we discover a contingency and integrate literatures on RISC and relational energy to better understand the consequences of workplace friendship. Altogether, the current study is at the forefront of exploring the impacts of workplace friendship through the lens of COR theory. Figure 1 presents our proposed research model.

\section{THEORY AND HYPOTHESES}

\section{Workplace Friendship and Interpersonal Citizenship}

Friendship is defined as "a relationship involving voluntary or unconstrained interaction in which the participants respond to one another personally, that is, as unique individuals rather than as packages of discrete attributes or mere role occupants" (Wright, 1984, p. 119). We suggest that workplace friendship is likely to encourage a focal employee to display interpersonal citizenship at work because interpersonal citizenship is also driven by voluntariness and socioemotional goal (Lam et al., 2016; Pillemer and Rothbard, 2018). Interpersonal citizenship occurs when employees assist others beyond their job requirements (Van Scotter and Motowidlo, 1996), and we expect that a focal employee would demonstrate interpersonal citizenship toward both friends and common work peers.

According to COR theory, social relationships are seen as a resource to the extent that they can provide valued resources (Hobfoll et al., 2018). As an overall indication of close interpersonal relationships in the workplace, workplace friendship can provide psychological and behavioral support (e.g., trustworthiness, information sharing) that are conducive to work (Sias and Cahill, 1998; Sias et al., 2012; Methot et al., 2016). In other words, interacting with friends at work can be emotionally fulfilling and can enrich employees' psychological resource (Lilius, 2012; Lam et al., 2016; Craig and Kuykendall, 2019). Workplace friendship can motivate employees to show interpersonal citizenship because of the harmonious, supportive, and friendly environment that the individual is immersed 


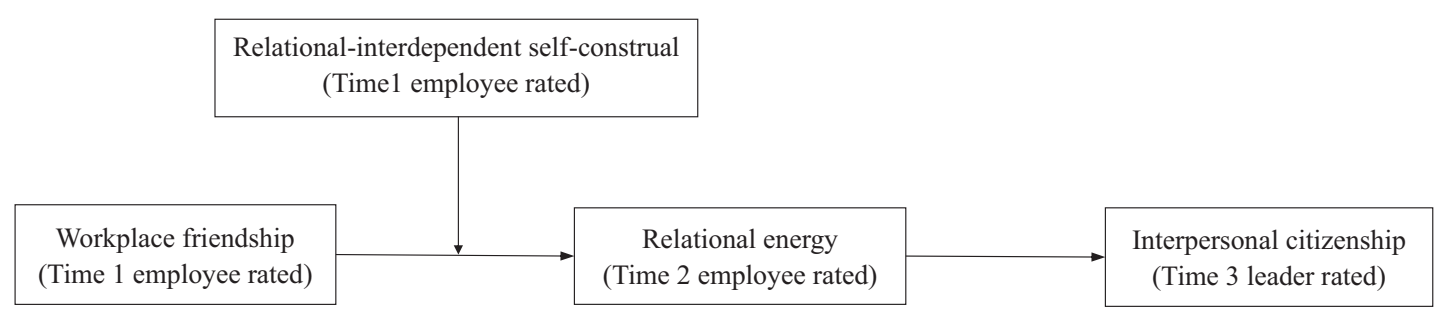

FIGURE 1 | The proposed model of current research.

in (Van Scotter and Motowidlo, 1996; Kim et al., 2013; Lam et al., 2016). Interpersonal citizenship at work includes cooperative, considerate, and helpful acts that assist coworkers' performance (Van Scotter and Motowidlo, 1996), which is in accordance with the characteristics that workplace friendship resembles. Moreover, interpersonal citizenship is a positive interpersonal activity that enhances an individual's positive affect (Koopman et al., 2016), facilitates social cohesiveness, and builds reciprocal ties with coworkers (Halbesleben and Wheeler, 2015). In particular, employees tend to have a desire to develop and progress with close friends, thus driving them to help their friends to finish tasks and achieve job goals (Sias and Cahill, 1998; Berman et al., 2002; Sias et al., 2012).

Furthermore, as Bowler and Brass (2006) noted that "it is not necessary for employees to help only those individuals that help them; they may pass on the help to others in a [pay it forward], pass it on manner" (p. 71). Similarly, interpersonal citizenship does not just happen between workplace friends, it can also be demonstrated to other common work peers. One important reason is that employees are inclined to enjoy and appreciate the benefits of workplace friendship, and thus display interpersonal citizenship to common work peers for the purpose of showing kindness and establishing bonding (Sias and Cahill, 1998; Bowler and Brass, 2006). For example, workplace friendship encourages mutual observational learning and advice seeking (Lee and Duffy, 2019). Therefore, we hypothesize the following:

Hypothesis 1: Workplace friendship is positively related to interpersonal citizenship.

\section{Relational Energy as a Linking Pin}

Energy is a resource that can increase an employee's capacity of motivation and action, thereby enabling one to perform and attain goals (Hobfoll, 1989; Quinn et al., 2012; Hobfoll et al., 2018). Energy can be derived from external stimulus, internal cognition, and relational interactions (Cole et al., 2012; Baker, 2019). Relational energy refers to the specific energy generated from interpersonal interactions, which can influence an employee's work outcomes (Owens et al., 2016; Wang et al., 2018; Yang et al., 2019). For example, employees can receive relational energy when interacting with their humble leaders because the behaviors entailed in expressed humility represent social cues that can be interpreted as a form of non-material social giving (e.g., giving esteem and license), which can subsequently enhance their job performance (Wang et al., 2018). We argue that friends at work can arouse employees' relational energy and then motivate them to display interpersonal citizenship.

Both of theoretical arguments and empirical evidences indicate that workplace friendship can foster relational energy. Friends, who provide trust, help, sense of meaning, and support at work, can be considered as a resource provider. Workplace friendship depicts an interactive schema of high interactional frequency and intense emotional injection (Jehn and Shah, 1997; Sias and Cahill, 1998; Ingram and Zou, 2008; Mao et al., 2012). Such relationship implies frequent face-to-face interactions wherein friends develop a mutual focus of attention and become entrained in each other's bodily micro rhythms and emotions (Collins, 2004). In addition, social contagion between friends is particularly salient, providing a potential mechanism in which human energy can be transmitted through social interactions (Hatfield et al., 1994; Owens et al., 2016). For example, studies have shown that working alongside friends can engender happiness and positive affect (Sias and Cahill, 1998; Lu et al., 2017). Sense of meaning can also be derived from workplace friendship (Rawlins, 1992), and is closely related to energy (Fritz et al., 2011).

Moreover, we propose that an employee with high relational energy is more likely to demonstrate interpersonal citizenship behavior, as energy derived from interpersonal interactions is particularly important in maintaining interpersonal relationships (Owens et al., 2016; Baker, 2019). More broadly speaking, energized employees have a stronger willingness and capacity to show interpersonal citizenship. First, energized individuals are interested in building a broader interpersonal network (Fritz et al., 2011; Cullen-Lester et al., 2016). To that end, employees are likely to show their interpersonal citizenship, as it is a way to convey their kindness and friendliness. Second, relational energy represents a heightened level of psychological resourcefulness that captures the motivation, vitality, stamina, and vigor that is generated from interpersonal exchange (Owens et al., 2016). Individuals with relational energy have abundant resources that can afford them to engage in other behaviors such as helping and caring (Halbesleben et al., 2014; Trougakos et al., 2015). Therefore, we hypothesize the following:

Hypothesis 2: Relational energy mediates the positive relationship between workplace friendship and interpersonal citizenship. 


\section{The Moderating Role of RISC}

Self-construal studies suggest that RISC is an important personality trait that can greatly influence interpersonal preferences and processes (Cross et al., 2000; Cross and Morris, 2003; Morry and Kito, 2009; Baker and McNulty, 2013). Employees with a RISC usually prioritize goals involving developing and maintaining the connectivity of self-defining relationships (Heintzelman and Bacon, 2015). These employees are more likely to consider others in the decision-making process (Gore et al., 2006), which promote communal norms such as enacting appropriate behaviors and fostering interpersonal harmony (Baker and McNulty, 2013). Since workplace friendship affects one's definition of the self, employees with different self-construals would interact with friends at work differently and thus are affected by friendship differently. As a result, the extent to which employees generate relational energy from workplace friendship is largely dependent on how they construe themselves in relation to others (Cristina-Corina, 2012).

Employees with a high RISC tend to place more value on connection and interdependence with others than those low in RISC (Gore et al., 2006). They are encouraged to promote and maintain interactions with others by engaging in behaviors such as accounting for the needs and wishes of others and empathizing others' feelings (Cross et al., 2000; Cross and Morris, 2003). We propose that higher RISC can strengthen the relationship between workplace friendship and relational energy. First, as employees with a high RISC are more sensitive to others' feelings and behaviors, they are more affected by interpersonal influences which allow them to establish a higher awareness of information exchange (Gore et al., 2006; Baker and McNulty, 2013). Second, social support from friends is especially valued by those with high RISC (Heintzelman and Bacon, 2015) because these individuals tend to experience more intense and emotional feelings from interpersonal interactions (Cross et al., 2000). Third, higher RISC is related to higher disclosure, which increases the frequency of interactions among friends (Morry and Kito, 2009). For these reasons, employees with a high RISC are more likely to be energized when interacting with friends.

In contrast, for employees with a low RISC, they do not view workplace friends as a vital factor in their self-construal (Cross and Morris, 2003). These individuals tend to derive self-meanings independent of social interactions, which means "Who am I" is likely to be answered with reference to internal traits that are stable across situations (Cross et al., 2011). As a result, their emotions and cognitions are less likely to be affected by others, which reduce the acquisition of relational energy from workplace friendship. Moreover, employees with a low RISC are more likely to judge workplace friendship as troublesome when behaviors required to fulfill instrumental goals conflict with socioemotional goals (Pillemer and Rothbard, 2018). Hence, the positive effect of workplace friendship on relational energy is reduced. Therefore, we hypothesize the following:

Hypothesis 3: RISC moderates the relationship between workplace friendship and relational energy, such that the relationship is stronger when RISC is high but weaker when it is low.

\section{A Moderated Mediation Model}

The above hypotheses describe a picture of the relationship between workplace friendship and interpersonal citizenship behavior that suggests relational energy plays a mediating role and employees with a high RISC are likely to derive more relational energy from their friends in the workplace. Taken together, we propose a first-stage moderated mediation for the effect of workplace friendship on interpersonal citizenship.

Hypothesis 4: RISC moderates the indirect relationship between workplace friendship and interpersonal citizenship via relational energy, such that the indirect relationship is stronger when RISC is high rather than low.

\section{MATERIALS AND METHODS}

\section{Samples and Procedures}

To test the theoretical model, we conducted a time-lagged (i.e., three time frames), multi-source (i.e., employees and their direct supervisors) survey study in a large public institution in southwestern China. Employees in this institution work in teams, and they have many opportunities to interact with each other in their daily work. The time-lagged, multisource survey design was employed to minimize common method variance (Podsakoff et al., 2003). We asked the human resource department to randomly organize potential participating employees, where we solicited their on-site voluntary participation by explaining our research purpose, assuring the confidentiality of their responses, and providing office supplies and monetary incentives. Specifically, we gave each participant a card holder and a pen. In addition, we set up a lottery at the end of each survey questionnaire. Monetary rewards ranged from 1 to 100 Chinese Yuan. In total, 1047 employees from 150 workgroups expressed interests in participating our study.

In the time 1 questionnaire, 947 employees (response rate $=90.45 \%$ ) from 132 workgroups returned their responses on workplace friendship, RISC, and demographic information. Two months later, we returned on-site and distributed the time 2 questionnaire, of which 856 employees (response rate $=81.76 \%$ ) from 118 workgroups reported their relational energy. Another 2 months later, we revisited the company and distributed the time 3 questionnaire, of which 108 supervisors (response rate $=72.00 \%$ ) answered their demographic information and assessed their subordinates' interpersonal citizenship. After matching employees to their respective workgroup supervisors via a unique identification code, our final sample consisted of 620 employees and 83 supervisors.

Among the sampled employees, $56.77 \%$ were male, $68.55 \%$ had earned a bachelor degree or above, and $53.86 \%$ had an organizational tenure of at least 5 years. The average age was $34.40(S D=8.15)$. For the supervisor sample, $43.37 \%$ were male, $72.29 \%$ had earned a bachelor degree or above, and $83.13 \%$ had an organizational tenure of at least 5 years. The average age was $37.17(S D=4.73)$. 


\section{Measures}

All of the scales used to measure the main variables were originally developed in English. We followed Brislin's (1980) translation and back-translation procedures to generate a Chinese version of measures. All of the main items were measured on a 5-point Likert scale ( $1=$ strongly disagree to $5=$ strongly agree). We calculated McDonald's Omega coefficient to test the reliability of each scale (McDonald, 1999), which has been suggested to be a sensible index of internal consistency (Zinbarg et al., 2005).

\section{Workplace Friendship}

Workplace friendship was rated on the 12-item scale developed by Nielsen et al. (2000) in the time 1 questionnaire. An example item was "Being able to see my coworkers is one reason why I look forward to my job” (McDonald's Omega $=0.93$ ).

\section{Relational-Interdependent Self-Construal}

Relational-interdependent self-construal was assessed on the 11-item scale generated by Cross et al. (2000) in the time 1 questionnaire. A sample item was "My close relationships are an important reflection of who I am" (McDonald's Omega $=0.98$ ).

\section{Relational Energy}

Relational energy was measured on the 5-item scale developed by Owens et al. (2016) in the time 2 questionnaire. We replaced "this person" to "my friends at work." Such operation can also be found in Wang et al. (2018) and Yang et al. (2019). An example item was "I feel invigorated when I interact with my friends at work” (McDonald’s Omega $=0.88)$.

\section{Interpersonal Citizenship}

Supervisors provided the ratings for employee interpersonal citizenship using the 7-item scale adopted by Van Scotter and Motowidlo (1996) in the time 3 questionnaire. A sample item was "This employee helps someone without being asked" (McDonald's Omega $=0.92)$.

\section{Analytic Technique}

Our data reflected a nested structure, with employees nested in workgroups led by a supervisor. Therefore, we used multilevel methods (i.e., random intercept models) to test the hypotheses at the employee-level of analysis (i.e., level 1), while taking possible group-level influence into account (i.e., level 2; Deng et al., 2018). Specifically, we used Mplus 7.4 (Muthén and Muthén, 2017) and employed the "cluster" and "type = two level random" syntaxes to perform the analyses. All independent variables were groupmean centered. To test for mediation effect, we adopted Selig and Preacher's (2008) Monte Carlo method to derive coefficient estimates and confidence intervals (CIs) at 95\% significance level with 20,000 sample repetitions. The Monte Carlo method has been suggested as a superior method than methods that rely on single point estimates (e.g., Sobel test; Preacher et al., 2010). To test for moderation effect, we evaluated the effect at "high" (one standard deviation above the mean) and "low" (one standard deviation below the mean) values of the moderator.

\section{DATA ANALYSIS AND RESULTS}

\section{Confirmatory Factor Analysis}

We conducted a series of confirmatory factor analyses to test the discriminant validity of our measurement model. As shown in Table 1, the fit indices of the hypothesized four-factor model are acceptable: chi-square $\left(\chi^{2}\right)=1522.82$, degrees of freedom $(d f)=550, p<0.001$; root mean square error of approximation $($ RMSEA $)=0.05$; comparative fit index $(\mathrm{CFI})=0.93$; Tucker Lewis index $(\mathrm{TLI})=0.92$; standardized root mean square residual $(\mathrm{SRMR})=0.05$. The four-factor model is superior to any other alternative models. Hence, construct distinctiveness of the main variables is established.

\section{Hypothesis Tests}

The means, standard deviations, inter-correlations, and internal consistencies of studied variables are presented in Table 2 . Hypothesis 1 predicts a positive relationship between workplace friendship and interpersonal citizenship. As shown in Table 3, workplace friendship is positively related to interpersonal citizenship $(B=0.27, S E=0.05, p<0.001)$. Hence, Hypothesis 1 is supported.

Hypothesis 2 argues that relational energy mediates the relationship between workplace friendship and interpersonal citizenship. To test for mediation effect, we first obtained coefficient estimates by regressing relational energy on workplace friendship, and interpersonal citizenship on relational energy, respectively. Subsequently, we inserted these coefficient estimates into the Monte Carlo analysis (with 20,000 sample repetitions). The results from the Monte Carlo analysis indicate that relational energy mediates the positive relationship between workplace

TABLE 1 | Comparison of measurement models.

\begin{tabular}{|c|c|c|c|c|c|c|c|c|}
\hline Models & $x^{2}$ & df & $\chi^{2} / \mathrm{df}$ & $\Delta \mathrm{x}^{2}(\mathrm{df})^{\mathrm{a}}$ & RMSEA & CFI & TLI & SRMR \\
\hline Hypothesized 4-factor model (WF, RISC, RE, IC) & 1522.82 & 550 & 2.77 & - & 0.05 & 0.93 & 0.92 & 0.05 \\
\hline Alternative 3-factor model (WF, RISC, RE + IC) & 2365.79 & 553 & 4.29 & $842.97^{\star \star \star}(3)$ & 0.07 & 0.87 & 0.86 & 0.09 \\
\hline Alternative 3-factor model (WF, RISC + RE, IC) & 2443.82 & 553 & 4.42 & $921.00^{\star \star \star}(3)$ & 0.07 & 0.86 & 0.85 & 0.10 \\
\hline Alternative 2-factor model (WF + RE + RISC, IC) & 5371.45 & 555 & 9.68 & $3848.63^{\star \star \star}(5)$ & 0.12 & 0.64 & 0.62 & 0.19 \\
\hline Alternative 1-factor model (WF + RISC + RE + IC) & 6871.53 & 556 & 12.36 & $5348.71^{\star \star \star}(6)$ & 0.14 & 0.53 & 0.50 & 0.21 \\
\hline
\end{tabular}

$N=620$ (employees), $N=83$ (workgroups). WF, workplace friendship; RISC, relational-interdependent self-construal; RE, relational energy; IC, interpersonal citizenship;

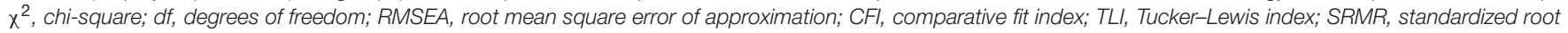
mean square residual. ${ }^{a}$ All models are compared with the hypothesized 4-factor model. ${ }^{* * *} p<0.001$. 
TABLE 2 | Means, standard deviations, inter-correlations, and internal consistencies of studied variables.

\begin{tabular}{|c|c|c|c|c|c|c|c|c|c|c|c|c|}
\hline Variables & Mean & $S D$ & 1 & 2 & 3 & 4 & 5 & 6 & 7 & 8 & 9 & 10 \\
\hline (1) Employee gender & 1.43 & 0.50 & - & & & & & & & & & \\
\hline (2) Employee age & 34.40 & 8.15 & $0.11^{\star \star}$ & - & & & & & & & & \\
\hline (3) Employee education & 2.88 & 0.73 & -0.05 & -0.06 & - & & & & & & & \\
\hline (4) Employee organizational tenure & 2.91 & 1.41 & 0.06 & $0.66^{\star \star \star}$ & -0.07 & - & & & & & & \\
\hline (5) Extraversion & 3.86 & 0.77 & 0.01 & -0.02 & $0.08^{*}$ & -0.04 & $(0.92)$ & & & & & \\
\hline (6) Positive affect & 3.93 & 0.55 & -0.00 & -0.04 & 0.03 & -0.06 & $0.43^{\star \star \star}$ & $(0.92)$ & & & & \\
\hline (7) Workplace friendship & 4.23 & 0.48 & 0.03 & -0.05 & -0.00 & -0.01 & $0.09^{*}$ & 0.08 & $(0.93)$ & & & \\
\hline (8) Relational energy & 3.86 & 0.54 & -0.02 & -0.03 & 0.01 & -0.06 & $0.18^{\star \star \star}$ & $0.23^{\star \star \star}$ & $0.39^{\star \star \star}$ & $(0.88)$ & & \\
\hline (9) RISC & 4.15 & 0.66 & 0.01 & 0.01 & 0.04 & -0.03 & 0.04 & 0.04 & $0.20^{\star \star \star}$ & $0.37^{\star \star \star}$ & $(0.98)$ & \\
\hline (10) Interpersonal citizenship & 3.81 & 0.55 & -0.04 & 0.03 & 0.07 & 0.03 & $0.21^{\star \star \star}$ & $0.22^{\star \star \star}$ & $0.23^{\star \star \star}$ & $0.34^{\star \star \star}$ & $0.12^{\star \star}$ & $(0.92)$ \\
\hline
\end{tabular}

$N=620$ (employees), $N=83$ (workgroups). RISC, relational-interdependent self-construal; SD, standard deviation. McDonald's Omegas are presented along the diagonal. Gender: 1 = male; 2 = female. Education: 1 = high school or below; 2 = junior college; 3 = bachelor; 4 = postgraduate. Organizational tenure: 1 = less than 1 year; $2=1-4$ years; $3=5-8$ years; $4=9-12$ years; $5=13-16$ years; $6=17$ years or above. ${ }^{*} p<0.05,{ }^{* *} p<0.01,{ }^{* *} p<0.001$.

TABLE 3 | Hierarchical linear modeling results.

\begin{tabular}{|c|c|c|c|c|}
\hline \multirow[t]{2}{*}{ Variables } & \multirow{2}{*}{$\frac{\text { Main effect }}{\text { Interpersonal citizenship }}$} & \multicolumn{2}{|c|}{ Mediation effect } & \multirow{2}{*}{$\begin{array}{l}\text { Moderation effect } \\
\text { Relational energy }\end{array}$} \\
\hline & & Relational energy & Interpersonal citizenship & \\
\hline Intercept & $2.68^{\star \star \star}(0.22)$ & $3.86^{\star \star \star}(0.02)$ & $2.59^{\star \star \star}(0.22)$ & $3.84^{\star \star \star}(0.02)$ \\
\hline \multicolumn{5}{|l|}{ Main predictors } \\
\hline Workplace friendship & $0.27^{\star \star \star}(0.05)$ & $0.42^{\star \star \star}(0.06)$ & $0.12^{\star}(0.05)$ & $0.36^{\star \star \star}(0.06)$ \\
\hline Relational energy & & & $0.32^{\star \star \star}(0.06)$ & \\
\hline Relational-interdependent self-construal (RISC) & & & & $0.28^{\star \star \star}(0.04)$ \\
\hline \multicolumn{5}{|l|}{ Interaction } \\
\hline Workplace friendship $\times$ RISC & & & & $0.30^{\star \star \star}(0.06)$ \\
\hline
\end{tabular}

$N=620$ (employees), $N=83$ (workgroups). Values in parentheses are standard error estimates. ${ }^{*} p<0.05,{ }^{* *} p<0.001$.

friendship and interpersonal citizenship (indirect effect $=0.13$, $S E=0.03,95 \% C I=[0.08,0.19])$. These findings provide support for Hypothesis 2.

Hypothesis 3 predicts that RISC moderates the relationship between workplace friendship and relational energy, such that the relationship is stronger when RISC is high but weaker when it is low. As shown in Table 3, results reveal a significant interaction $(B=0.30, S E=0.06, p<0.001)$. Figure 2 illustrates the form of this interaction by plotting the simple slopes at "high" and "low" values of RISC. As shown in Table 4, first-stage effects indicate that the relationship between workplace friendship and relational energy is stronger in condition of high RISC $(B=0.56, S E=0.07$, $p<0.001)$, but weaker in condition of low RISC $(B=0.16$, $S E=0.07, p<0.05$; difference $=0.40, S E=0.09, p<0.001)$. Hence, Hypothesis 3 is supported.

Hypothesis 4 theorizes that RISC moderates the indirect relationships between workplace friendship and interpersonal citizenship via relational energy, such that the indirect relationship is stronger when RISC is high rather than low. We investigated the indirect effects at "high" and "low" values of RISC. The results as well as the CIs generated from the Monte Carlo analysis (with 20,000 sample repetitions) are presented in Table 4. As indicated, the indirect effect of workplace friendship on interpersonal citizenship via relational energy is stronger when RISC is "high" (indirect effect $=0.18, S E=0.04$, $95 \% C I=[0.10,0.25]$ ), and weaker when it is "low" (indirect effect $=0.05, S E=0.03,95 \% C I=[0.004,0.10]$; difference $=0.13$, $S E=0.03,95 \% C I=[0.06,0.19])$. Altogether, these results provide support for Hypothesis 4. The path analysis results are presented in Figure 3.

\section{Supplementary Analysis}

To ensure the robustness of our findings, we also included several control variables in our supplementary analysis. Previous research has pointed out that the effects of workplace friendship can be influenced by gender, as men tend to focus on shared activities while women emphasize shared emotions (Morrison, 2009). Consistent with existing research on workplace friendship, three other demographic variables were controlled, which are age, education, and organizational tenure (Chen et al., 2012; Methot et al., 2016). Considering that extraverts are more likely to develop and participate in interpersonal activities (CullenLester et al., 2016; Methot et al., 2016), we controlled for employee extraversion using the Mini-IPIP scale (Donnellan et al., 2006; McDonald's Omega = 0.92). In addition, people who have positive affectivity tend to experience more positive emotions (Vandenberghe et al., 2018), which may influence the level of relational energy. Thus, we also controlled for employee positive affect using Watson et al.'s (1988) Positive and Negative Affect Schedule (McDonald's Omega = 0.92). In sum, we included control variables of gender, age, education, organizational tenure, extraversion, and positive affect in our supplementary analysis. 


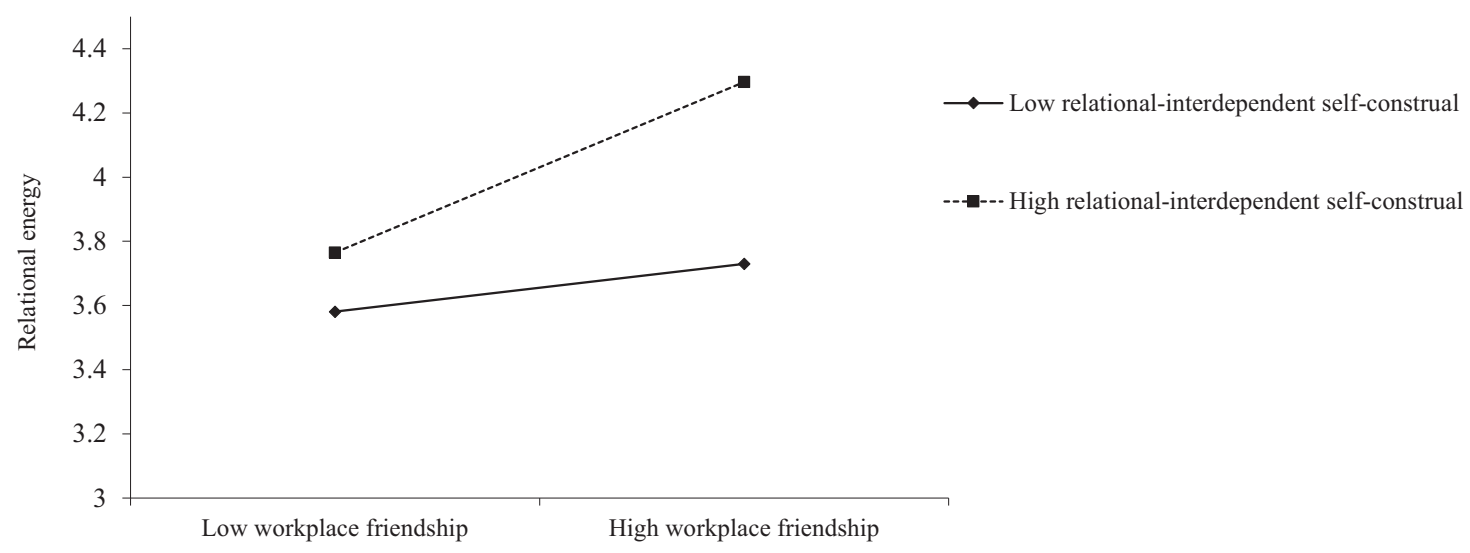

FIGURE 2 | The interactive effect of workplace friendship and relational-interdependent self-construal on relational energy.

TABLE 4 | First-stage, second-stage, and conditional indirect effect results.

\begin{tabular}{|c|c|c|c|c|c|}
\hline Outcome & $\frac{\text { Moderator }}{\text { RISC }}$ & \multicolumn{2}{|c|}{ Stage } & \multicolumn{2}{|c|}{ Effect } \\
\hline & High (+1 SD) & $0.56^{\star \star \star}(0.07)$ & $0.32^{\star \star \star}(0.06)$ & $0.18^{\star \star \star}(0.04)$ & {$[0.10,0.25]$} \\
\hline & Difference & $0.40^{\star \star \star}(0.09)$ & - & $0.13^{\star \star \star}(0.03)$ & {$[0.06,0.19]$} \\
\hline
\end{tabular}

$N=620$ (employees), $N=83$ (workgroups). RISC, relational-interdependent self-construal; SD, standard deviation. $P_{\mathrm{mx}}$, path from workplace friendship to relational energy; $P_{y m}$, path from relational energy to interpersonal citizenship. Values in parentheses are standard error estimates. Results from regression analyses were entered into the online utility developed by Selig and Preacher (2008). Monte Carlo resampling method (with 20,000 sample repetitions) was adopted to estimate confidence intervals (Cls) at $95 \%$ significance. ${ }^{*} p<0.05,{ }^{* * *} p<0.001$.

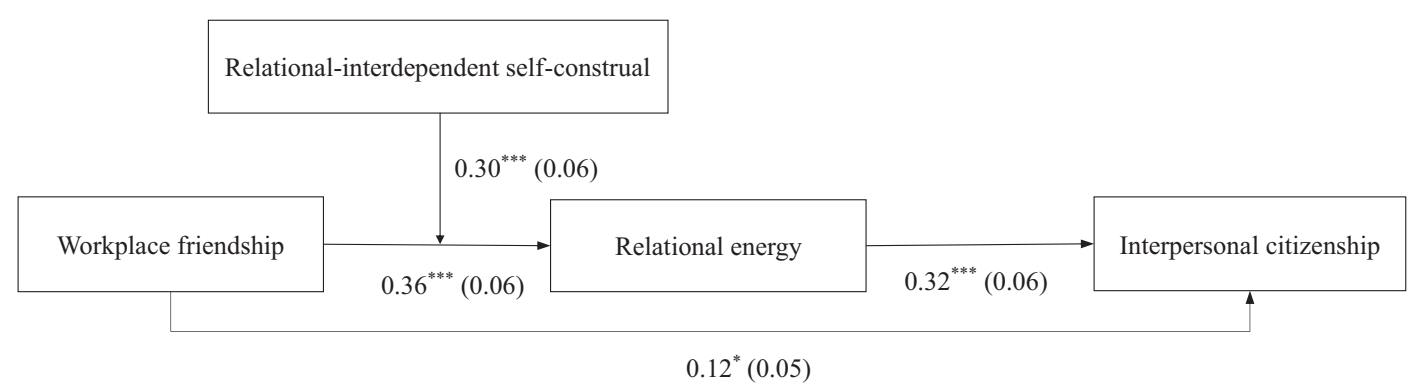

FIGURE 3 | Path analysis results. ${ }^{*} p<0.05,{ }^{* * *} p<0.001$

The results show a significant relationship between workplace friendship and interpersonal citizenship $(B=0.24, S E=0.05$, $p<0.001)$. In terms of the mediation effect, relational energy mediates the positive relationship between workplace friendship and interpersonal citizenship (indirect effect $=0.11, S E=0.05$, 95\% CI $=[0.06,0.16])$. Moreover, the moderating effect of RISC on the relationship between workplace friendship and relational energy is significant $(B=0.30, S E=0.06, p<0.001)$. Further, the indirect effect of workplace friendship on interpersonal citizenship via relational energy is stronger when RISC is "high" (indirect effect $=0.14, S E=0.03,95 \% C I=[0.08,0.21]$ ) than when RISC is "low" (indirect effect $=0.04, S E=0.02$, 95\% CI $=[0.003,0.09] ;$ difference $=0.11, S E=0.03,95 \%$ $C I=[0.05,0.16])$. The results of the supplementary analysis show that the significance levels of all the hypothesized relationships remained the same when control variables were included (versus excluded) in the supplementary analysis, which suggests that our findings, to a large extent, are robust.

\section{DISCUSSION}

To better understand the influence of workplace friendship, scholars have increasingly called for nuanced perspectives that identify the process and outcomes of workplace friendship. In this research, we take a major step forward in this regard. That is, we adopt COR theory to explore how workplace friendship stimulates relational energy which fosters 
interpersonal citizenship, and the condition that affects the saliency of this relationship. Using data from 620 employees nested in 83 workgroups, we demonstrated that relational energy mediates the relationship between workplace friendship and interpersonal citizenship. Moreover, we found that this relationship is more salient for employees with a high RISC.

\section{Theoretical Implications}

Our findings extend prior literature in multiple ways. First, in order to explore workplace friendship's influence on interpersonal citizenship, we adopt COR theory to support our rationale. Recently, the COR perspective has been argued as a promising theoretical framework for studying the consequences of workplace friendship (Methot et al., 2016; Hood et al., 2017). The present study enhances understanding in this regard. Specifically, unlike previous studies that focused on an individual's particular affective experience derived from interacting with one's workplace friends, we treat affective experiences collectively as a source of energy that facilitates an individual's interpersonal behavior. In doing so, we are able to find supporting evidence for elevated interpersonal citizenship behavior as a positive consequence of workplace friendship. In addition, previous research has often adopted a social exchange perspective to explain why positive interpersonal relationship can promote interpersonal citizenship (Farmer et al., 2015). However, this approach is more suitable in explaining interpersonal citizenship behavior directed back at the target of exchange, whereas it is less adequate in explaining interpersonal citizenship behavior demonstrated toward others (Cropanzano et al., 2017). The COR theory, on the other hand, provides a different perspective, as it suggests that individuals' actions are affected by the acquisition of valued resource.

Second, we empirically test the COR framework by proposing and examining the mediating role of elevated resource in explaining the effect of workplace friendship on interpersonal citizenship. Specifically, we theorize relational energy as an important resource likely to be enhanced in response to workplace friendship, which further stimulates employees' interpersonal citizenship behavior. Relatedly, existing literature has mainly linked relational energy to leader-subordinate interactions (Owens et al., 2016; Wang et al., 2018; Yang et al., 2019), because leaders, who are perceived as representatives of the organization, can energize their subordinates. We argue that friends in the workplace can also be a source that generates relational energy for a focal employee, as friends tend to interact with each other more and thus result in greater contagion of emotions. In doing so, we empirically answer Owens et al.'s (2016) call for investigating whether employee can receive relational energy from other interpersonal relationships besides one of leader-subordinate.

Third, our study highlights RISC as the boundary condition in the process of generation of relational energy and demonstration of interpersonal citizenship as consequences of workplace friendship. Support for the moderation effect provides novel and interesting insights for understanding how an interpersonal tendency can strengthen and weaken the consequences of workplace friendship. We found that when employees' selfconstrual is more affected by social interactions, they are more likely to garner relational energy from their workplace friends, which subsequently, facilitates their interpersonal behavior. Other recent research has also begun to explore the boundary conditions of the influences of workplace friendship (e.g., Methot et al., 2016; Pillemer and Rothbard, 2018), suggesting that adopting an interactionist perspective is important and necessary to understand the influences of friendship in a workplace setting.

\section{Limitations and Future Research}

The present study includes several limitations that highlight important avenues for future research. First, we encourage future scholars to investigate our theoretical model by adopting more rigorous methodological designs. Specifically, although we adopted a time-lagged, multi-source survey design, we are still not able to make strong causal inferences or rule out the possibility of reverse causality. For instance, employees who exhibit interpersonal citizenship may be more likely to generate relational energy or establish new workplace friendship. Thus, we encourage future research to adopt survey studies of a longitudinal design or experiment studies to address our model's causality.

Second, our samples were drawn in a Chinese context. Research has suggested that the Chinese culture places great value on interpersonal relationship and harmony (Farh et al., 1998). Hence, workplace friendship may be more important and valued in a collectivist society, as opposed to in an individualistic society. In addition, it is not uncommon for employees of different cultural backgrounds to work together in a workplace environment (Khaleel et al., 2018). Since people of different cultural backgrounds can interpret workplace friendship differently and thus have different behavioral tendencies toward maintaining such friendship (Cross et al., 2000; Cross and Morris, 2003; Cristina-Corina, 2012), examining the consequences of workplace friendship in an integrated cultural context can also yield interesting and meaningful results. Therefore, we also encourage future studies to use different samples, preferably drawing samples from different cultural contexts, to examine the generalizability of our findings.

Third, recent research has begun to study workplace friendship using a social network approach (Methot et al., 2016; Hood et al., 2017; Tasselli and Kilduff, 2018). This approach highlights that an individual is "in the thick of things", and that interpersonal relationships are more dynamic in nature (Methot et al., 2016). Furthermore, such approach has the advantage of moving analysis beyond the employee's general perception of workplace friendship to a consideration of the structure and characteristics of the various relationships that the employee entertains in the workplace (Hayton et al., 2012). Specifically, the social network approach provides two network models (i.e., relational model and positional model) to explain the social influencing process. Relational model implies that social influence is operated through the mechanisms of cohesion and solidarity, where individuals are influenced by relational others. That is, individuals enjoy close social proximity with those whom they directly interact (Burkhardt, 1994). On the other 
hand, positional model emphasizes that individuals tend to pay attention to people whose positions are similar to those of theirs in the informal social structure (Burkhardt, 1994). Considering that individuals have direct interactions and enjoy close social proximity with friends in the workplace, we suggest future studies to adopt the relational model of social network to conceptualize and capture the influences of workplace friendship. In this way, workplace friends can be regarded as an important source of information, help, and support (Ho and Levesque, 2005).

Finally, we also urge future studies to adopt different theoretical lens to explore and enrich the consequences of workplace friendship. For instance, drawing upon optimal distinctiveness theory, high-quality interpersonal relationships can promote helping behavior through enhanced identification with exchange partners (Farmer et al., 2015). Self-determination theory may be another potential theoretical framework, as it can explain the relationship between workplace friendship and work-related outcomes from the perspective of basic psychological needs (Gagné and Deci, 2005). Furthermore, while we explored an individual difference as a boundary condition of the relationship between workplace friendship and relational energy, we suggest that contextual influences can also be critical contingencies worthy of investigation. For example, as a mechanistic unit structure is characterized by centralization of control and authority and extensive specialization and standardization of task (Aryee et al., 2008), it may reduce the frequency of interactions among friends, thereby weakening the relationship between workplace friendship and energy derived from interpersonal interactions.

\section{Managerial Implications}

Workplace friendship is more prevalent nowadays because of the flatter organizational hierarchy which facilitates social interactions (Ingram and Zou, 2008). Our study provides important implications for managerial practice. First, our findings reveal that workplace friendship has constructive influence on employees' interpersonal citizenship behavior, which suggests that developing and maintaining workplace friendship are important and conducive to employees' interpersonal behavior. Hence, we suggest managers to foster work climates that facilitate the development of workplace friendship. They can organize more team-building activities and promote teamwork in order to increase employees' opportunities to develop and enhance personal bonding. They can also facilitate interpersonal interactions among employees by, for example, assigning more team tasks and allocating more rewards to the achievement of these tasks.

Second, our findings show that relational energy is positively related to employee interpersonal citizenship. Previous studies also found that energy is a fuel that allows employees to selfmotivate and engage in constructive work behavior (Quinn et al., 2012). Energized employees are able to develop more intimate relationships with their teammates, thereby contributing to team functioning through relevant behaviors such as information sharing (Sias et al., 2012; Cullen-Lester et al., 2016). Therefore, managers should be aware of and monitor employees' energy levels (Schwartz and McCarthy, 2007). For example, managers can show more caring, trust, and encouragement to employees in their daily work. In doing so, their energy level can be enhanced, resulting in improved interpersonal citizenship.

Third, our findings reveal that workplace friendship exerts a stronger influence on employee interpersonal citizenship for those with a high RISC. This is possibly because that individuals with a high RISC tend to create a harmonious interpersonal climate when working with others. Thus, organizations are suggested to consider individual RISC as an essential criterion when selecting candidates for positions that require substantial teamwork. Moreover, organizations should allocate employees with an independent self-construal to positions that require fewer social interactions. Overall, organizations should emphasize the importance of interpersonal relationships during employee training and equip employees with necessary techniques to acquire and enhance relevant social skills.

\section{CONCLUSION}

The present study investigates a moderated mediation model linking workplace friendship to employee interpersonal citizenship via relational energy. Moreover, we highlight the importance of RISC as a moderator affecting the consequences of workplace friendship. The moderated mediation model provides a comprehensive and clear understanding of the influences of friendship in the workplace. We hope that the theoretical and practical insights gained in this study will enrich understanding of workplace friendship and encourage researchers to further explore its consequences.

\section{DATA AVAILABILITY STATEMENT}

The dataset generated for this study is available upon request to the corresponding author.

\section{ETHICS STATEMENT}

Ethical review and approval were not required for the study. Informed consent was obtained from all participants in the study.

\section{AUTHOR CONTRIBUTIONS}

JX designed and conducted the study and drafted the manuscript. J-YM and TQ edited the manuscript. J-YM and JQ conducted the data analysis. All authors discussed, finalized, and approved the manuscript for publication.

\section{FUNDING}

This research was funded by the Chinese National Funding of Social Sciences, No. 16BGL097, and the Fundamental Research Funds for the Central Universities (JBK2001026). 


\section{REFERENCES}

Aryee, S., Sun, L. Y., Chen, Z. X. G., and Debrah, Y. A. (2008). Abusive supervision and contextual performance: the mediating role of emotional exhaustion and the moderating role of work unit structure. Manage. Organ. Rev. 4, 393-411. doi: 10.1111/j.1740-8784.2008.00118.x

Baker, L. R., and McNulty, J. K. (2013). When low self-esteem encourages behaviors that risk rejection to increase interdependence: the role of relational selfconstrual. J. Pers. Soc. Psychol. 104, 995-1018. doi: 10.1037/a0032137

Baker, W. E. (2019). Emotional energy, relational energy, and organizational energy: toward a multilevel model. Ann. Rev. Organ. Psychol. Organ. Behav. 6, 373-395. doi: 10.1146/annurev-orgpsych-012218-015047

Berman, E. M., West, J. P., and Richter, M. N. Jr. (2002). Workplace relations: friendship patterns and consequences (according to managers). Public Adm. Rev. 62, 217-230. doi: 10.1111/0033-3352.00172

Bowler, W. M., and Brass, D. J. (2006). Relational correlates of interpersonal citizenship behavior: a social network perspective. J. Appl. Psychol. 91, 70-82. doi: 10.1037/0021-9010.91.1.70

Brislin, R. W. (1980). "Translation and content analysis of oral and written materials," in Handbook of Cross-Cultural Psychology, eds H. C. Triandis, and J. W. Berry (Boston, MA: Allyn and Bacon), 389-444.

Burkhardt, M. E. (1994). Social interaction effects following a technological change: a longitudinal investigation. Acad. Manage. J. 37, 869-898. doi: 10.5465/256603

Chen, C. Y., Mao, H. Y., and Hsieh, A. T. (2012). Role ambiguity, employee gender, and workplace friendship. Psychol. Rep. 110, 719-730. doi: 10.2466/01.07.21. PR0.110.3.719-730

Cole, M. S., Bruch, H., and Vogel, B. (2012). Energy at work: a measurement validation and linkage to unit effectiveness. J. Organ. Behav. 33, 445-467. doi: 10.1002/job.759

Collins, R. (2004). Interaction Ritual Chains. Princeton, NJ: Princeton University Press.

Craig, L., and Kuykendall, L. (2019). Examining the role of friendship for employee well-being. J. Vocat. Behav. 115:103313. doi: 10.1016/j.jvb.2019.06.001

Cristina-Corina, B. (2012). Independent-interdependent self-construal's and values' appreciation in competitive and cooperative conditions. Procedia Soc. Behav. Sci. 47, 1632-1637. doi: 10.1016/j.sbspro.2012.06.875

Cropanzano, R., Anthony, E. L., Daniels, S. R., and Hall, A. V. (2017). Social exchange theory: a critical review with theoretical remedies. Acad. Manag. Ann. 11, 479-516. doi: 10.5465/annals.2015.0099

Cross, S. E., Bacon, P. L., and Morris, M. L. (2000). The relational-interdependent self-construal and relationships. J. Pers. Soc. Psychol. 78, 791-808. doi: 10.1037/ 0022-3514.78.4.191

Cross, S. E., Hardin, E. E., and Gercek-Swing, B. (2011). The what, how, why, and where of self-construal. Pers. Soc. Psychol. Rev. 15, 142-179. doi: 10.1177/ 1088868310373752

Cross, S. E., and Morris, M. L. (2003). Getting to know you: the relational selfconstrual, relational cognition, and well-being. Pers. Soc. Psychol. Bull. 29, 512-523. doi: 10.1177/0146167202250920

Cullen-Lester, K. L., Leroy, H., Gerbasi, A., and Nishii, L. (2016). Energy's role in the extraversion (dis)advantage: how energy ties and task conflict help clarify the relationship between extraversion and proactive performance. J. Organ. Behav. 37, 1003-1022. doi: 10.1002/job.2087

Deng, H., Guan, Y., Wu, C. H., Erdogan, B., Bauer, T., and Yao, X. (2018). A relational model of perceived overqualification: the moderating role of interpersonal influence on social acceptance. J. Manage. 44, 3288-3310. doi: $10.1177 / 0149206316668237$

Donnellan, M. B., Oswald, F. L., Baird, B. M., and Lucas, R. E. (2006). The miniIPIP scales: tiny-yet-effective measures of the big five factors of personality. Psychol. Assess. 18, 192-203. doi: 10.1037/1040-3590.18.2.192

Farh, J. L., Tsui, A. S., and Cheng, X. B. S. (1998). The influence of relational demography and guanxi: the Chinese case. Organ. Sci. 9, 471-488. doi: 10.2307/ 2640274

Farmer, S. M., Van Dyne, L., and Kamdar, D. (2015). The contextualized self: how team-member exchange leads to coworker identification and helping OCB. J. Appl. Psychol. 100, 583-595. doi: 10.1037/a0037660

Fritz, C., Lam, C. F., and Spreitzer, G. M. (2011). It's the little things that matter: an examination of knowledge workers' energy management. Acad. Manage. Exec. 25, 28-39. doi: 10.5465/AMP.2011.63886528
Gagné, M., and Deci, E. L. (2005). Self-determination theory and work motivation. J. Organ. Behav. 26, 331-362. doi: 10.2307/4093832

Gore, J. S., Cross, S. E., and Morris, M. L. (2006). Let's be friends: relational self-construal and the development of intimacy. Pers. Relat. 13, 83-102. doi: 10.1111/j.1475-6811.2006.00106.x

Halbesleben, J. R. B., Neveu, J. P., Paustian-Underdahl, S. C., and Westman, M. (2014). Getting to the "COR": understanding the role of resources in conservation of resources theory. J. Manage. 40, 1334-1364. doi: 10.1177/ 0149206314527130

Halbesleben, J. R. B., and Wheeler, A. R. (2015). To invest or not? the role of coworker support and trust in daily reciprocal gain spirals of helping behavior. J. Manage. 41, 1628-1650. doi: 10.1177/0149206312455246

Hatfield, E., Cacioppo, J. T., and Rapson, R. L. (1994). Emotional Contagion. New York, NY: Cambridge University Press.

Hayton, J. C., Carnabuci, G., and Eisenberger, R. (2012). With a little help from my colleagues: a social embeddedness approach to perceived organizational support. J. Organ. Behav. 33, 235-249. doi: 10.1002/job.755

Heintzelman, S. J., and Bacon, P. L. (2015). Relational self-construal moderates the effect of social support on life satisfaction. Pers. Indiv. Differ. 73, 72-77. doi: 10.1016/j.paid.2014.09.021

Ho, V. T., and Levesque, L. L. (2005). With a little help from my friends (and substitutes): social referents and influence in psychological contract fulfillment. Organ. Sci. 16, 275-289. doi: 10.1287/orsc.1050.0121

Hobfoll, S. E. (1989). Conservation of resources: a new attempt at conceptualizing stress. Am. Psychol. 44, 513-524. doi: 10.1037/0003-066X.44.3.513

Hobfoll, S. E., Halbesleben, J., Neveu, J. P., and Westman, M. (2018). Conservation of resources in the organizational context: the reality of resources and their consequences. Ann. Rev. Organ. Psychol. Organ. Behav. 5, 103-128. doi: 10. 1146/annurev-orgpsych-032117-104640

Hood, A. C., Cruz, K. S., and Bachrach, D. G. (2017). Conflicts with friends: a multiplex view of friendship and conflict and its association with performance in teams. J. Bus. Psychol. 32, 73-86. doi: 10.1007/s10869-016-9436-y

Ingram, P., and Zou, X. (2008). Business friendships. Res. Organ. Behav. 28, 167-184. doi: 10.1016/j.riob.2008.04.006

Jehn, K. A., and Shah, P. P. (1997). Interpersonal relationships and task performance: an examination of mediation processes in friendship and acquaintance groups. J. Pers. Soc. Psychol. 72, 775-790. doi: 10.1037/0022-3514. 72.4.775

Khaleel, M., Chelliah, S., Jamil, M., and Khalid, J. (2018). The "What", "Why" and "How" of friendship at multinational workplace: a critical review. Adv. Sci. Lett. 24, 3102-3105. doi: 10.1166/asl.2018.11325

Kim, Y. J., Van Dyne, L., Kamdar, D., and Johnson, R. E. (2013). Why and when do motives matter? an integrative model of motives, role cognitions, and social support as predictors of OCB. Organ. Behav. Hum. Dec. Proc. 121, 231-245. doi: 10.1016/j.obhdp.2013.03.004

Koopman, J., Lanaj, K., and Scott, B. A. (2016). Integrating the bright and dark sides of OCB: a daily investigation of the benefits and costs of helping others. Acad. Manage. J. 59, 414-435. doi: 10.5465/amj.2014.0262

Lam, C. F., Wan, W. H., and Roussin, C. J. (2016). Going the extra mile and feeling energized: an enrichment perspective of organizational citizenship behaviors. J. Appl. Psychol. 101, 379-391. doi: 10.1037/apl0000071

Lee, K., and Duffy, M. K. (2019). A functional model of workplace envy and job performance: when do employees capitalize on envy by learning from envied targets? Acad. Manage. J. 62, 1085-1110. doi: 10.5465/amj.2016.1202

Lilius, J. M. (2012). Recovery at work: understanding the restorative side of "depleting" client interactions. Acad. Manage. Rev. 37, 569-588. doi: 10.5465/ amr.2010.0458

Liu, J., Kwan, H. K., Fu, P. P., and Mao, Y. (2013). Ethical leadership and job performance in china: the roles of workplace friendships and traditionality. J. Occup. Organ. Psychol. 86, 564-584. doi: 10.1111/joop.12027

Lu, J. G., Hafenbrack, A. C., Eastwick, P. W., Wang, D. J., Maddux, W. W., and Galinsky, A. D. (2017). "Going out" of the box: close intercultural friendships and romantic relationships spark creativity, workplace innovation, and entrepreneurship. J. Appl. Psychol. 102, 1091-1108. doi: 10.1037/apl000 0212

Mao, H. Y., Hsieh, A. T., and Chen, C. Y. (2012). The relationship between workplace friendship and perceived job significance. J. Manage. Organ. 18, 247-262. doi: 10.1017/S1833367200000985 
McDonald, R. P. (1999). Test Theory: A Unified Approach. Mahwah, NJ: Lawrence Erlbaum Associates.

Methot, J. R., Lepine, J. A., Podsakoff, N. P., and Christian, J. S. (2016). Are workplace friendships a mixed blessing? Exploring tradeoffs of multiplex relationships and their associations with job performance. Pers. Psychol. 69, 311-355. doi: 10.1111/peps.12109

Morrison, R. L. (2009). Are women tending and befriending in the workplace? Gender differences in the relationship between workplace friendships and organizational outcomes. Sex Roles 60, 1-13. doi: 10.1007/s11199-008-9513-4

Morry, M. M., and Kito, M. (2009). Relational-interdependent self-construal as a predictor of relationship quality: the mediating roles of one's own behaviors and perceptions of the fulfillment of friendship functions. J. Soc. Psychol. 149, 305-322. doi: 10.3200/SOCP.149.3.305-322

Muthén, L. K., and Muthén, B. O. (2017). Mplus User's Guide, 8th Edn. Los Angeles, CA: Muthén and Muthén.

Nielsen, I. K., Jex, S. M., and Adams, G. A. (2000). Development and validation of scores on a two-dimensional workplace friendship scale. Educ. Psychol. Meas. 60, 628-643. doi: 10.1177/00131640021970655

Owens, B. P., Baker, W. E., Sumpter, M. D., and Cameron, K. S. (2016). Relational energy at work: implications for job engagement and job performance. J. Appl. Psychol. 101, 35-49. doi: 10.1037/apl0000032

Pillemer, J., and Rothbard, N. P. (2018). Friends without benefits: understanding the dark sides of workplace friendship. Acad. Manage. Rev. 43, 635-660. doi: 10.5465/amr.2016.0309

Podsakoff, P. M., Mackenzie, S. B., Lee, J. Y., and Podsakoff, N. P. (2003). Common method biases in behavioral research: a critical review of the literature and recommended remedies. J. Appl. Psychol. 88, 879-903. doi: 10.1037/0021-9010. 88.5.879

Preacher, K. J., Zyphur, M. J., and Zhang, Z. (2010). A general multilevel SEM framework for assessing multilevel mediation. Psychol. Meth. 15, 209-233. doi: $10.1037 / \mathrm{a} 0020141$

Quinn, R. W., and Dutton, J. E. (2005). Coordination as energy-in-conversation. Acad. Manage. Rev. 30, 36-57. doi: 10.5465/amr.2005.15281422

Quinn, R. W., Spreitzer, G. M., and Lam, C. F. (2012). Building a sustainable model of human energy in organizations: exploring the critical role of resources. Acad. Manage. Ann. 6, 337-396. doi: 10.5465/19416520.2012.676762

Rath, T. (2006). Vital Friends: The People you Can't Afford to Live Without. New York, NY: Gallup Press.

Rawlins, W. K. (1992). Friendship Matters: Communication, Dialectics, and the Life Course. New Brunswick, NJ: Trans-action Publishers.

Schwartz, T., and McCarthy, C. (2007). Manage your energy, not your time. Harv. Bus. Rev. 85, 63-73. doi: 10.1109/AFRCON.2013.6757587

Selig, J. P., and Preacher, K. J. (2008). Monte Carlo Method for Assessing Mediation: an Interactive Tool for Creating Confidence Intervals for Indirect Effects [Computer Software]. Available at: http://quantpsy.org/medmc/medmc. htm (accessed August 6, 2019).

Sias, P. M., and Cahill, D. J. (1998). From coworkers to friends: the development of peer friendships in the workplace. West. J. Commun. 6, 273-299. doi: 10.1080/ 10570319809374611
Sias, P. M., Pedersen, H., Gallagher, E. B., and Kopaneva, I. (2012). Workplace friendship in the electronically connected organization. Hum. Commun. Res. 38, 253-279. doi: 10.1111/j.1468-2958.2012.01428.x

Tasselli, S., and Kilduff, M. (2018). When brokerage between friendship cliques endangers trust: a personality-network fit perspective. Acad. Manage. J. 61, 802-825. doi: 10.5465/amj.2015.0856

Trougakos, J. P., Beal, D. J., Cheng, B. H., Hideg, I., and Zweig, D. (2015). Too drained to help: a resource depletion perspective on daily interpersonal citizenship behaviors. J. Appl. Psychol. 100, 227-236. doi: 10.1037/a0038082

Tse, H. H. M., Dasborough, M. T., and Ashkanasy, N. M. (2008). A multi-level analysis of team climate and interpersonal exchange relationships at work. Leadersh. Q. 19, 195-211. doi: 10.1016/j.leaqua.2008.01.005

Van Scotter, J. R., and Motowidlo, S. J. (1996). Interpersonal facilitation and job dedication as separate facets of contextual performance. J. Appl. Psychol. 81, 525-531. doi: 10.1037/0021-9010.81.5.525

Vandenberghe, C., Panaccio, A., Bentein, K., Mignonac, K., Roussel, P., and Ayed, A. K. B. (2018). Time-based differences in the effects of positive and negative affectivity on perceived supervisor support and organizational commitment among newcomers. J. Organ. Behav. 40, 264-281. doi: 10.1002/job.2324

Wang, L., Owens, B. P., Li, J., and Shi, L. (2018). Exploring the affective impact, boundary conditions, and antecedents of leader humility. J. Appl. Psychol. 103, 1019-1038. doi: 10.1037/apl0000314

Watson, D., Clark, L. A., and Tellegen, A. (1988). Development and validation of brief measures of positive and negative affect: the PANAS scales. J. Pers. Soc. Psychol. 54, 1063-1070. doi: 10.1037/0022-3514.54.6.1063

Winstead, B. A., Derlega, V. J., Montgomery, M. J., and Pilkington, C. (1995). The quality of friendships at work and job satisfaction. J. Soc. Pers. Relat. 12, 199-215. doi: 10.1177/0265407595122003

Wright, P. H. (1984). Self-referent motivation and the intrinsic quality of friendship. J. Soc. Pers. Relat. 1, 115-130. doi: 10.1177/026540758401 1007

Yang, F., Liu, J., Wang, Z., and Zhang, Y. (2019). Feeling energized: a multilevel model of spiritual leadership, leader integrity, relational energy, and job performance. J. Bus. Ethics 158, 983-997. doi: 10.1007/s10551-017-3713-1

Zinbarg, R., Revelle, W., Yovel, I., and Li, W. (2005). Cronbach's $\alpha$, Revelle's $\beta$, and McDonald's $\omega$ : their relations with each other and two alternative conceptualizations of reliability. Psychometrika 70, 122-133. doi: 10.1007/ s11336-003-0974-7

Conflict of Interest: The authors declare that the research was conducted in the absence of any commercial or financial relationships that could be construed as a potential conflict of interest.

Copyright (c) 2020 Xiao, Mao, Quan and Qing. This is an open-access article distributed under the terms of the Creative Commons Attribution License (CC BY). The use, distribution or reproduction in other forums is permitted, provided the original author(s) and the copyright owner(s) are credited and that the original publication in this journal is cited, in accordance with accepted academic practice. No use, distribution or reproduction is permitted which does not comply with these terms. 